\section{EMBRYRIDDLE}

Aeronautical University

SCHOLARLY COMMONS
Journal of Aviation/Aerospace

Education \& Research

Volume 30

Number 2 JAAER 2021

Article 2

2021

\title{
Emergency Preparedness and Response Education in Aviation \\ Management Programs in the United States
}

Heather L. Servaty-Seib

Purdue University, West Lafayette, servaty@purdue.edu

Andrew Brown

Purdue University, West Lafayette, brow1239@purdue.edu

Follow this and additional works at: https://commons.erau.edu/jaaer

Part of the Educational Leadership Commons, Emergency and Disaster Management Commons, and the Higher Education Commons

\section{Scholarly Commons Citation}

Servaty-Seib, H. L., \& Brown, A. (2021). Emergency Preparedness and Response Education in Aviation Management Programs in the United States. Journal of Aviation/Aerospace Education \& Research, 30(2). https://doi.org/10.15394/jaaer.2021.1897

This Article is brought to you for free and open access by the Journals at Scholarly Commons. It has been accepted for inclusion in Journal of Aviation/Aerospace Education \& Research by an authorized administrator of Scholarly Commons. For more information, please contact commons@erau.edu. 


\section{Introduction}

Although aviation disasters are relatively uncommon, the severity of mass injuries and fatalities is of concern. The number of fatal aviation accidents in the United States has steadily decreased from 350 in 1997 to 225 in 2018, with annual fatalities also decreasing from 631 to 393 (National Transportation Safety Board [NTSB], n.d.). Of the 393 deaths in 2018, one was associated with an airline, 12 were associated with air taxis, and 381 were categorized as general aviation (NTSB notes that "totals may not equal the sum of all categories as some accidents may be counted in multiple categories"). In addition, the total accident rate per 100,000 flight hours has similarly decreased from 7.04 (2012) to 5.88 (2018) with accidents most often occurring En Route and during Landing. In comparison, the number of deaths associated with highway accidents in 2018 was 36,560 . Despite the encouraging decline in aviation-related fatalities, the deaths noted here indicate a substantial loss of life and represent significant impact on surviving family members and aviation employees.

Much attention and curricular coverage in aviation management programs is rightfully placed on topics of safety and prevention. In fact, courses on risk management and safety are included as standard practice in plans of study and in aviation accreditation standards (Aviation Accreditation Board International [AABI], 2021). Less is known about how often and to what extent aviation management programs cover topics associated with emergency preparedness and response (EPR). The purpose of the present study was to determine, through surveying department heads, the extent of curricular coverage devoted to the topics of emergency preparedness and response education in aviation management programs in the United States.

With continuing mergers and acquisitions in the airline industry, aviation-related

businesses in the United States (i.e., private or commercial) are likely to experience a fatal airline 
accident at some point. Regional carriers are even more likely to face this situation. Managing a fatal airline accident requires the balancing of many critical issues, only a few of which include airport and station response (Crichton, 2014), agency coordination (Smith, 2010), principles of humanitarian response (Adams, 2016), and brand protection (Grundy \& Moxon, 2013). In addition, although all employees will not necessarily be involved in the first response to an accident, such events can have wide-reaching impact across organizations. The sheer complexity and scope of all that must be considered when managing a fatal airline accident suggests the need for inclusion of such training within aviation management degree programs.

Oderman (2002) offered two primary justifications for the need for ethics education in aviation which also apply to the need for EPR education. First, he argued that ethics is being taught even if it is not a formal element of the curriculum. Most specifically he noted that if programs are silent on a topic, such as ethics or in the current case EPR, the message to students is that the topic is not important. Second, he argued that other fields have used models for effectively teaching the topic of ethics. In the case of EPR, effective curriculum and core competencies exist for training medical (Jasper et al., 2017; Kaji, et al., 2010) and nursing (Gebbie \& Qureshi, 2002; Jose \& Dufrene, 2014) students. In particular, students have positively perceived disaster simulation training with reported enhanced understanding and confidence (Kaplan et al., 2011, Morrison \& Catanzaro, 2010; Summerhill et al., 2008). Resources for EPR education are available through aviation-related publications that offer guidance regarding standards, regulations, and best practices (e.g., Schreckengast, 2000; Sledzig \& Bryson, 2016; National Academy of Sciences, 2015), EPR post-degree aviation-focused training programs (e.g., IATA, NTSB, Aircraft Rescue and Fire Fighting), and non-aviation EPR training programs (e.g., World Health Organization, US Environmental Protection Agency). 
Airport managers have a regulatory obligation, as part of their Airport Certification under 14 Code of Federal Regulations (CFR) Part 139, to "develop and maintain an airport emergency plan designed to minimize the possibility and extent of personal injury and property damage on the airport..." (Airport Emergency Plan). The Aviation Disaster Family Assistance Act (ADFAA) of 1996 and the Federal Family Assistance Plan for Aviation Disasters (FFAPAD) of 1999 require airlines to have organized and consistent responses to disasters, including a requirement that airlines provide appropriate disaster-related education/training to their personnel.

Although accidents are rare, it is likely that aviation professionals will be required to respond in either a proximal or distal way to an aviation incident or disaster. Solid knowledge and skills connected to EPR would contribute to aviation professionals' confidence and effectiveness in responding to such situations. The extent to which EPR education occurs in aviation educational programs is currently unknown. The present study investigates the extent to which heads of departments that include aviation management programs value EPR as a topic, and how available the topic is to students enrolled in their programs.

Participants responded to items in a variety of areas, including personal background, university and department information, curricular inclusion of EPR, attitudes toward inclusion of EPR coverage in curricula, perspectives on funding EPR training, perceived obstacles to the inclusion of EPR coverage in curricula, department climate regarding EPR, and the differential importance of a list of possible topics to be included in instruction on EPR. 


\section{Research Methodology}

This section includes a description of the methodology used for the present study. More specifically, information is offered regarding the participants, measures, and procedure.

\section{Participants}

The final sample $(N=26)$ consisted of heads or acting heads of academic departments with aviation management programs within the United States (please see Procedure section for recruitment information). They had served as head for an average of approximately six years ( $M$ $=5.89, S D=6.15$; Range 0 to 20 years) and, prior to becoming head, had been faculty members for an average of seven years ( $M=6.96, S D=8.17$; Range 0 to 37 years). Since receiving their degrees, they had been employed in the aviation industry for an average of 20 years $(M=20.19$, $S D=13.01 ;$ Range 0 to 45 years). Participants indicated a variety of positions held in industry with over half $(n=14)$ being current or former pilots. Other past positions included aerospace engineer, customer service, air traffic controller, crew commander, airport supervisor, director of human factors, airline co-founder, and safety officer. Dotan et al. (2017) surveyed leaders of academic departments of ophthalmology and found an average of seven years as head, a similar range of years of industry experience, and a comparable broad range of positions/subspecialities.

Of relevance to the present study, $73.1 \%(n=19)$ indicated never having to respond to an aviation accident with $26.9 \%(n=7)$ indicating that they had. Of those who had, the average number of accidents they had responded to was three $(M=3.14, S D=3.13$, Range of 1 to 10$)$. Participants rated their experience with emergency preparedness and response (EPR) on a fivepoint scale $(1=$ none to $5=$ a great deal $)$, and the resulting average was at the mid-point of the scale $(M=3.08, S D=1.38)$. 


\section{Measures}

The questionnaire used in the present study was a modified version of the one developed by Oderman (2003) in his investigation of ethics education within U.S. aviation management programs. With permission, the assessment of curricular inclusion of EPR was based on the approach Oderman (2003) used to determine ethics inclusion in aviation management programs (D. B. Oderman, personal communication, September 11, 2015). More specifically, EPR-course related information provided by department heads was used to assign a rating from 1 to 7 to each department on how much EPR instruction was currently included in their curricula. The questions used were focused on whether EPR was addressed as a planned topic in an elective or required course, in an elective course principally devoted to EPR, and/or as a required course principally devoted to EPR. We assigned ratings using the following scale: $1=$ No curricular coverage, 2 = Planned Topic, $3=$ Elective, $4=$ Elective and Planned Topic, $5=$ Required, $6=$ Required and Elective, and $7=$ Required, Elective, and Planned Topic. Through this approach, departments with no coverage received the lowest rating, whereas those with broad EPR integration received the highest rating. All areas of assessment below were aligned with the approach used by Oderman (2003).

\section{EPR Teaching}

The 6-item measure of EPR teaching is focused on whether there are any professors within the department who teach required or elective classes principally devoted to EPR or classes where EPR is a planned topic. In addition, the measure assesses whether department heads have taught any courses focused on EPR. Participants offer dichotomous responses $(1=$ yes, $0=$ no) to each item and the total score is the sum of the responses with higher scores indicating greater EPR teaching emphasis within the department. Example items include, "Does 
a professor in your aviation management department teach at least one required course for aviation management students that is principally devoted to EPR?" and "Have you personally ever taught an elective course that is principally devoted to EPR?" Using scores from the current sample, Cronbach's alpha was .84. Cronbach's alpha is a measure of internal consistency, that is, how closely related a set of items are as a group. It indicates scale reliability and .70 and above is considered good internal consistency.

\section{Attitude Toward EPR Inclusion}

The 5-item measure of attitude toward EPR inclusion is focused on department heads' perspectives on the inclusion of EPR instruction, even if they are not currently offering courses that address the topic. Participants rate each item on a 5 -point scale $(1=$ strongly disagree to $5=$ strongly agree), and the total score is the sum of the responses, with higher scores indicating a greater degree of positive attitude toward EPR inclusion. Example items include, "Students majoring in aviation management at my institution should be required to take at least one course that is principally devoted to EPR in order to meet degree requirements," and "Emergency preparedness and response should be taught/discussed in all applicable aviation courses whenever the topics related to EPR are appropriate to the courses being taught." Using scores from the current sample, Cronbach's alpha was .75. Open-ended questions in this section included: "What do you believe are the advantages of offering a course on emergency preparedness and response?" and "What do you believe are the disadvantages of offering a course on emergency preparedness and response?"

\section{Attitude Toward Funding EPR Inclusion}

The 3-item measure of attitude toward funding EPR inclusion is focused on department heads' perspectives on how likely they would be to use existing funds to prepare faculty, initiate 
or enhance teaching, and/or to develop material for EPR inclusion. Participants rate each item using a 5 -point scale $(1=$ strongly disagree to $5=$ strongly agree $)$, and the total score is the sum of the responses with higher scores indicating a greater degree of positive attitude toward using existing funds. Example items include, "In my current position, given the same funding my department now receives, I have already or would be willing to devote funds to prepare aviation management professors to teach EPR" and "In my current position, given the same funding my department now receives, I have already or would be willing to devote funds toward course material development for EPR courses within the aviation management curriculum.” Using scores from the current sample, Cronbach's alpha was .96.

\section{Obstacles to EPR Inclusion}

The 7-item measure of obstacles to EPR inclusion is focused on department heads' perspectives on the obstacles that would make inclusion difficult. Participants rate each item on a 5-point $(1=$ strongly disagree to $5=$ strongly agree $)$ scale, and the total score is the sum of the responses with higher scores indicating a greater perception of obstacles. Example items include, "I have overcome or would have to overcome lack of higher-level university administration support in order to include EPR instruction as part of my aviation management curriculum" and "I have overcome or would have to overcome lack of time in an already packed curriculum in order to include EPR instruction as part of my aviation management curriculum." Using scores from the current sample, Cronbach's alpha was .81. Open-ended questions in this section included: "What other factors or circumstances would make it difficult or impossible for you to offer a course on emergency preparedness and response?" and "What factors or circumstances would enable you to offer a course on emergency preparedness and response?" 


\section{EPR Department Climate}

In alignment with Oderman's (2003) approach to assessing curricular coverage of ethics, the 3-item measure of EPR department climate used focused on how much EPR is a part of the administrative, rather than the teaching, aspects of the department. Participants offer dichotomous responses $(1=$ yes, $0=$ no) to each item and the total score is the sum of the responses with higher scores indicating more positive EPR department climate. Example items include, "Does your department have an EPR plan?" and "Have you had guest speakers, seminars, or educational meetings to address issues related to including EPR in your department's curriculum?" Using scores from the current sample, Cronbach's alpha was .74.

\section{Procedure}

A list of names and email addresses of 83 heads of departments in the US that included aviation management programs was generated through reviewing the websites of both the Aviation Accreditation Board International (AABI) and the Experimental Aviation Association (EAA). In addition, the list was cross-checked by searching Google for additional educational programs focused on "aviation management" and to find emails that were not available on the AABI and EAA websites. Programs were included regardless of level of training (e.g., associate, baccalaureate). Following the receipt of research exemption status from the university institutional research board, the recruitment message was emailed to department heads. The message included a brief description of the study and the link to the online survey. Participants had the option to receive a $\$ 25$ Amazon.com gift card in connection with their participation.

\section{Results}

A total of 33 department heads initially responded to the survey for an overall response rate of $40 \%$. Dotan et al. (2017) received a similar response rate of $50 \%$ from heads of academic 
departments of ophthalmology. Missing data reduced the number to 27 participants. In addition, one participant read the information letter for the study and decided not to participate, bringing the final sample to 26 . The total $n$ varies throughout as a few participants left some items blank; the correct $n$ is offered for each analysis.

\section{University and Program Information}

As indicated in Table 1, the two most common Carnegie Classifications of Institutions of Higher Education represented in the data were Undergraduate College and R1 Doctoral University.

\section{Table 1}

Carnegie Classifications of Institutions of Higher Education $(n=25)$

\begin{tabular}{lcc}
\hline Classification & Frequency & Percentage \\
& & \\
R1: Doctoral University & 6 & $23.1 \%$ \\
R2: Doctoral University & 4 & $15.4 \%$ \\
R3: Doctoral University & 1 & $3.8 \%$ \\
MS2: Master's College/University & 1 & $3.8 \%$ \\
MS3: Master's College/University & 1 & $3.8 \%$ \\
Undergraduate College & 8 & $30.8 \%$ \\
Undergraduate/Associates & 2 & $7.7 \%$ \\
Associates College & 2 & $7.7 \%$ \\
\hline
\end{tabular}

Department heads indicated the level of their aviation management programs (i.e., they generally indicated more than on level) as the following: four Associate's, 23 Baccalaureate, seven Master's, and three Doctoral. Table 2 includes specifics regarding the number of students enrolled and number of courses offered across the four program levels. 


\section{Table 2}

Number of Students and Courses Across Program Levels

Students $\underline{\text { Mean }(\mathrm{SD})}$

Associate $(\mathrm{n}=4)$

Baccalaureate $(\mathrm{n}=21)$

Master's $(\mathrm{n}=6)$

Doctoral $(\mathrm{n}=3)$
$113.50(191.22)$

$223.00(349.97)$

$29.17(36.90)$

$8.33(7.64)$ $\underline{\text { Range }}$

$5-400$

$18-1450$

$0-100$

$0-15$
Courses

$\underline{\text { Mean (SD) }} \underline{\text { Range }}$

$22.33(32.72 \quad 1-60$

$14.10(7.60) \quad 2-30$

$4.00(2.45) \quad 0-6$

$2.33(2.08) \quad 0-4$

The expected faculty teaching load for programs ranged from 2.50 to 12 courses per semester $(M=4.08, S D=1.80)$ and the actual teaching load ranged from 2 to 12 courses per semester $(M=4.25, S D=1.93)$. Department heads reported an average personal teaching load of just above two courses per semester $(M=2.31, S D=1.10)$.

\section{EPR Inclusion}

Regarding EPR curricular inclusion, programs received ratings across the scale from $1=$ No curricular coverage to $7=$ Required, Elective, and Planned Topic (see Table 3 ). The average level of inclusion was below the mid-point of the scale at $3.27(S D=2.09)$ and just above a rating of $3=$ Elective. More than half of programs had either no coverage or addressed EPR as a planned topic in an elective or required course. 


\section{Table 3}

Program Ratings on the EPR Curricular Inclusion Scale.

\begin{tabular}{lcc}
\hline & Frequency & Percentage \\
& 4 & $15.4 \%$ \\
$1=$ No Curricular Inclusion & 9 & $34.6 \%$ \\
$2=$ Planned Topic & 2 & $7.7 \%$ \\
$3=$ Elective & 3 & $11.5 \%$ \\
$4=$ Elective and Planned Topic & 2 & $7.7 \%$ \\
$5=$ Required & 0 & $0.0 \%$ \\
$6=$ Required and Elective & 4 & $15.4 \%$ \\
$7=$ Required, Elective, and Planned Topic & & \\
\end{tabular}

\section{EPR Instruction Level}

When prompted to consider which level they believed was the best fit for EPR instruction, $80.8 \%(n=21)$ indicated Baccalaureate, $46.2 \%(n=12)$ indicated Master's, $23.1 \%$ $(n=6)$ indicated Associate's and 15.4\% $(n=4)$ indicated Doctoral. Percentages do not total as participants could select more than one level.

Breaking down the courses offered at the Baccalaureate level, Table 4 includes specifics regarding the number of courses with each type of EPR coverage. Half of the department heads who responded regarding a Baccalaureate program indicated no required or elective course principally devoted to EPR. However, $85 \%$ indicated having at least one required course where EPR was covered as a planned topic. The course offerings at the other levels were much lower. At the Associate's level, one department head reported one course principally devoted to EPR, two reported one required course where EPR was covered as a planned topic, and two reported one elective course where EPR was a covered as a planned topic. At the Master's level, two department heads indicated one required course where EPR was covered as a planned topic. At 
the Doctoral level, one department head indicated one elective course where EPR was covered as a planned topic.

\section{Table 4}

Baccalaureate Programs and Varying Types of EPR Course Coverage

\begin{tabular}{ccc}
\hline & Program & Program \\
Number of Required or Elective Courses Principally Devoted & Frequency & Percentage \\
\cline { 2 - 3 } 0 & 13 & 50.0 \\
1 & 5 & 19.2 \\
2 & 3 & 11.5 \\
Number of Required Courses as Planned Topic & & \\
0 & 4 & 15.4 \\
1 & 8 & 30.8 \\
2 & 7 & 26.9 \\
3 & 2 & 7.7 \\
Number of Elective Courses as Planned Topic & 10 & 38.5 \\
0 & 8 & 30.8 \\
1 & 2 & 7.7 \\
2 & 1 & 3.8 \\
5 & & \\
\hline
\end{tabular}

\section{EPR Curricular Inclusion: Department Heads’ Background}

As indicated in Table 5, a department heads' years in the aviation industry was positively associated with both their experience with EPR and with their likelihood of having been a responder in an aviation accident. In contrast, years in the aviation industry was negatively associated with department heads' willingness to use existing department funds to prepare faculty, to initiate or enhance EPR teaching, or to develop teaching material related to EPR. Taken together, department heads who had been in the field longer were more likely to have EPR experience and less likely to be willing to use funds to support the teaching of EPR in their aviation management program(s). EPR experience was also positively associated with EPR Teaching (i.e., whether there were any professors within the department, including the 
department head, who teach required or elective classes principally devoted to EPR or have EPR as a planned topic). The more EPR experience department heads had the more likely they were to be leading departments where faculty, perhaps even themselves, were teaching courses that covered EPR topics.

Table 5|

Relationships Among Primary Variables

$\begin{array}{llllllllll}1 & 2 & 3 & 4 & 5 & 6 & 7 & 8 & 9 & 10\end{array}$

Mean (SD)

1. Length as Head $5.89(6.15) \quad--$

2. Years as Faculty Member $6.96(8.17) \quad-.23 \quad--$

3. Years in Aviation Industry $20.19(12.61) \quad .11 \quad .24 \quad--$

4. Experience with EPR $3.08(1.38) \quad .01 \quad-.24 \quad .39 * \quad--$

5. Responder to Accident $\begin{array}{llllll}\text { NA } & .20 & -.09 & .50 * * & .41 * & --\end{array}$

6. EPR Teaching $\begin{array}{lllllll}2.44(2.00) & .08 & -.32 & .26 & .71 * * & .22 & --\end{array}$

7. Attitude EPR Inclusion $18.32(3.68) \quad .03 \quad .21$

8. Funding EPR Inclusion $8.56(3.12) \quad .0$ $\begin{array}{lll}-.21 & -.55^{* *} \quad-.07\end{array}$ $-.03 \quad-34 \quad--$

9. EPR Inclusion Obstacles $21.52(4.87) \quad-.39$

10. EPR Department Climate

11. EPR Curricular Inclusion $1.00(1.17) \quad-.24$

$.20-.08$ $\begin{array}{llll}.03 & -.11 & -.02 & --\end{array}$

$-.22$

.40

\section{EPR Curricular Inclusion: Department Heads' Perceptions and Attitudes}

To more fully examine the possible contributors to the degree of inclusion and integration of EPR into program curricula, a simultaneous multiple regression was performed using EPR curricular inclusion as the dependent variable. Based on the correlations indicated in Table 5, EPR Teaching, Attitude toward EPR Inclusion, and EPR Department Climate were entered as the independent variables. As indicated in Table 5, Funding EPR Inclusion and EPR Inclusion Obstacles were not significantly associated with EPR curricular inclusion and, therefore, they were not included as independent variables in the regression. 
The analysis yielded a significant regression model accounting for $73.4 \%$ of the variance in EPR curricular inclusion, $\mathrm{R}^{2}=.73, F(3,21)=16.57, p<.001$ (see Table 6$)$. EPR Teaching $(\beta$ $=.57, p=.007)$ and Attitude Toward EPR Inclusion $(\beta=.32, p=.050)$ were significant positive predictors of EPR curricular inclusion. The results indicated that EPR curricular inclusion was more broadly integrated in departments where more faculty, including department heads, were teaching EPR courses and in departments with heads who indicated an attitude that EPR should be included in aviation management program curricula.

\section{Table 6}

Results of Multiple Regression Predicting EPR Curricular Inclusion and Integration

\begin{tabular}{lcccc}
\hline & $\underline{\mathrm{B}}$ & $\underline{\mathrm{SE}}$ & $\underline{\beta}$ & $\underline{\mathrm{sr}^{2}}$ \\
EPR Teaching & 0.63 & 0.15 & 0.57 & .27 \\
Attitude Toward EPR Inclusion & 0.20 & 0.10 & 0.32 & .06 \\
EPR Department Climate & 0.32 & 0.25 & 0.18 & .02 \\
\hline
\end{tabular}

Responses to the open-ended questions offer additional information regarding department heads' attitudes toward EPR inclusion. The vast majority indicated the importance of EPR training because students need the practical knowledge and because it would increase their marketability. Resources emerged as a primary bimodal theme in that the ability to integrate EPR training into curricula hinged on funding as well as faculty expertise and interest. Department heads also commented on the overloaded and inflexible content of curricula as key obstacles to EPR inclusion. In contrast, two participants expressed minority opinions that EPR training should not be offered in aviation management programs with one indicating that it would lead students to believe that accidents are inevitable and the other offering that EPR is a better fit for on-the-job training than it is for curricular inclusion. 
In terms of potential facilitators of EPR inclusion, no department heads reported receiving gifts or grants from outside their college/university related to incorporating EPR into their curriculums. However, one reported receiving an internal gift or grant related to incorporating EPR. When asked if they had faculty doing research in the area of EPR, 23.1\% ( $n$ =6) of heads responded in the affirmative. A higher percentage reported having faculty who had demonstrated an interest in teaching EPR $(50.0 \%, n=13)$ and who had initiated efforts (e.g., attended workshops) related to teaching EPR $(34.6 \%, n=9)$.

\section{Importance of EPR Topics}

Department heads rated the importance $(1=$ not at all important to $5=$ extremely important) of 16 possible topics to be included in EPR instruction (S. Warner-Bean, personal communication, March 1,2016). These areas are displayed in Table 7 in descending order of rated importance. Department heads were provided with a list of subtopics under each broad topic area (contact authors for full listing of subtopics). 


\section{Table 7}

EPR Topic Areas in Descending Order of Importance $(n=23)$

\begin{tabular}{ll} 
& Mean (SD) \\
Airport and Station Reponses & $4.35(.83)$ \\
Planning & $4.13(1.101)$ \\
Effective Crisis Leadership & $4.00(1.13)$ \\
Agency Coordination & $3.91(1.04)$ \\
Communications & $3.87(1.06)$ \\
Family Assistance Data and Information Management & $3.86(1.08)$ \\
Disaster Mental Health & $3.83(.94)$ \\
Principles of Humanitarian Response & $3.78(.85)$ \\
Special Assistance Team (SAT) (Family Liaisons or "Care Team”) & $3.74(1.21)$ \\
Media Relations & $3.70(1.06)$ \\
Telephone Enquiry Center & $3.70(1.02)$ \\
Family Assistance Requirements and Standards & $3.61(1.08)$ \\
Victim Accounting & $3.61(1.03)$ \\
Facilities & $3.61(1.08)$ \\
Practical Exercises & $3.57(.99)$ \\
Post Response Organization & $3.48(.99)$ \\
& \\
\hline
\end{tabular}

As indicated by the ratings, all areas were viewed as above the scale mid-point so all were considered at least moderately important. The highest rated topics appear focused on planning, coordination, roles, and responsibilities, whereas those with the lowest ratings appear more focused on details of implementation and follow-up.

\section{Conclusion}

The current findings suggest the need for enhanced EPR curricular coverage in aviation management programs. Department heads indicated challenges related to funding, faculty interest, and faculty expertise. However, the strongest quantitative predictors of EPR curricular integration/inclusion were the EPR teaching experiences of department heads and their general attitude toward EPR coverage. 
Interestingly, there was a negative relationship between department heads' EPR teaching experience and their willingness to spend funds on EPR. Those with the experience may be more focused on teaching the course(s) themselves rather than using departmental resources to train or hire other faculty. The longer department heads had been in the field, the more likely they were to have had personal experience with EPR and the less likely they were to support funding EPR curricular coverage. It may be that these department heads did not have EPR training in their programs (i.e., attended prior to such inclusion) so they may be less likely to see the current need. However, it may also be that their personal experience with an aviation disaster has taught them that no education can fully prepare individuals for the lived reality of such situations.

Although the trend toward more mass injuries versus mass fatalities in aviation disasters is encouraging, incidents will continue to occur and will, therefore, need to be managed. Department heads appear to be key gatekeepers in increasing the extent to which EPR is included in aviation management program curricula. Educating department heads on EPR may encourage them to serve as champions for curricular coverage, regardless of the barriers that may exist. In addition, the development of a standardized curriculum for EPR could be a practical tool for programs and for faculty who are open to including EPR as a planned topic in their courses or to teaching entire courses dedicated to EPR. A substantial step toward the inclusion and integration of EPR in aviation management programs would be for the University Aviation Association and the AABI to include EPR as recommended content in aviation programs.

A limitation of the current study was the low sample size. Although the response rate was reasonable, the small number of department heads who participated limits the confidence and generalizability of the findings. Future research would benefit from a larger sample size, perhaps through the inclusion of aviation management programs beyond those in the United 
States. As department heads are not the sole decision makers regarding curriculum, collecting data from faculty engaged in such decisions (e.g., chairs of curriculum committees) would be advantageous. Future researchers could expand the survey to solicit data about whether EPR was explicitly included as a course outcome and questions regarding faculty teaching loads would add important context to the findings.

An empirical implication of the current findings is the need for subsequent investigations of airline and airport managers working in the field. More specifically, it would be useful to determine what degrees they received and the extent to which their programs included training in EPR. Additional areas to be assessed would include how important they view EPR as part of their current positions and whether they believe EPR education is best done within degree programs, post-degree, or at both levels.

Aviation is a field highly invested in safety management system (SMS) programs and plans - and a field also affected by disasters. Critical attention must be given to mitigating risk and yet disasters cannot always be prevented. EPR is a form of tertiary prevention (i.e., focus on those already affected in order to limit complications and restore functioning). Being prepared for aviation disasters is beneficial on many levels (e.g., psychological, organizational, economic, legal, societal). Although implementation details and follow-up procedures were rated as lower in EPR topic importance by department heads (see Table 7), these areas are pivotal in enhancing the preventative power of EPR.

EPR training is not an endeavor that can be completed in anyone setting or at any one point in time. It is a complex process that involves many entities with various roles and responsibilities. Educational programs that train aviation managers can strengthen the future of the field by better preparing their graduates to appropriately manage disasters. Such training 
within formalized educational programs would reduce the need for aviation organizations to train new employees in EPR or offer them the opportunity to build upon the foundation already provided within degree programs. EPR training has the potential to bolster the confidence and coping of all aviation graduates, including those who are not intentionally planning to be directly engaged in EPR efforts.

When EPR management is based on solid knowledge (e.g., federal regulations, EPR best practices) and skills (e.g., flexibility, adaptability, and steadiness) and is marked by compassion, authenticity, and humanity, it can and does make a real difference in the lives of victims, surviving family members (e.g., Eyre, 2004), and aviation employees (e.g., Downing, 2004) as well as in the success and sustainability of the business endeavor. 


\section{References}

Airport Emergency Plan, 14 C.F.R. § 139.325 (September 2018).

https://www.law.cornell.edu/cfr/text/14/139.325

Adams, L. M. (2016). Promoting disaster resilience through use of interdisciplinary teams: A program evaluation of the integrated care team approach. World Medical and Health Policy, 8, 8-26. http://dx.doi.org/10.1002/wmh3.176

Aviation Accreditation Board International (AABI). (2021). Accreditation Criteria Manual, Form 201. http://www.aabi.aero/wp-content/uploads/2021/09/AABI-201-AccreditationCriteria-Manual-Rev.-7-16-21.pdf

Crichton, G. (2014). Learning from history: The Glasgow airport terrorist attack. Journal of Business Continuity \& Emergency Planning, 8, 169-180.

Dotan, G., Qureshi, H. M., Saraf, S. S., \& Darnley-Fisch, D. A. (2017). Leadership of United States departments of ophthalmology: Chairperson characteristics, accomplishments, and personal insights. American Journal of Ophthalmology, 186, 69-76. https://doi.org/10.1016/j.ajo.2017.10.024

Downing, J. R. (2004). American Airlines' use of mediated employee channels after the 9/11 attacks. Public Relations Review, 30, 37-48. https://doi.org/10.1016/j.pubrev.2003.11.004

Eyre, A. (2004). Psychosocial aspects of recovery: Practical implications for disaster managers. The Australian Journal of Emergency Management, 19, 23-27.

Gebbie, K. M., \& Qureshi, K. (2002). Emergency and disaster preparedness: Core competencies for nurses: What every nurse should but may not know. American Journal of Nursing, 102, 46-51. http://dx.doi.org/10.1097/00000446-200201000-00023 
Grundy, M., \& Moxon, R. (2013). The effectiveness of airline crisis management on brand protection: A case study of British Airways. Journal of Air Transportation Management, 28, 55-61. http://dx.doi.org/10.1016/j.jairtraman.2012.12.011

Jasper, E. H., Wanner, G. K., Berg, D., \& Berg, K. (2017). Implementing a disaster preparedness curriculum for medical students. Southern Medical Journal, 110, 523-527. http://dx.doi.org/10.14423/SMJ.0000000000000681

Jose, M. M., \& Dufrene, C. (2014). Educational competencies and technologies for disaster preparedness in undergraduate nursing education: An integrative review. Nurse Education Today, 34, 543-551. http://dx.doi.org/10.1016/j.nedt.2013.07.021

Kaji, A. H., Coates, W., \& Fung, C. (2010). A disaster medicine curriculum for medical students. Teaching and Learning in Medicine, 22, 116-122. http://dx.doi.org/10.1080/10401331003656561

Kaplan, B. G., Connor, A., Ferranti, E. P., Holmes, L., \& Spencer, L. (2011). Use of an emergency preparedness disaster simulation with undergraduate nursing students. Public Health Nursing, 29, 44-51. http://dx.doi.org/10.1111/j.1525-1446.2011.00960.x

Morrison, A. M., \& Catanzaro, A. M. (2010). High-fidelity simulation and emergency preparedness. Public Health Nursing, 27, 164-173. http://dx.doi.org/10.1111/j.15251446.2010.00838.x

National Academy of Sciences. (2015). Airport emergency post-event recovery practices: A synthesis of airport practice (Airport Cooperative Research Program [ACRP] Synthesis 60). Transportation Research Board of the National Academies. https://doi.org/10.17226/22151 
National Transportation Safety Board (NTSB). (n.d.). https://www.ntsb.gov/safety/data/Pages/Data_Stats.aspx

Oderman, D. B. (2002). Ethics education in university aviation management programs in the US: Part one-The need. Journal of Air Transportation, 7, 3-32.

Oderman, D. B. (2003). Ethics education in university aviation management programs in the U.S.: Part two — The current status. Journal of Air Transportation, 8, 15-36.

Schreckengast, S. (2000). Airline/airport emergency planning. In G.F. Butler \& M.R. Keller (Eds.), Handbook of Airline Operations (pp. 101-111). McGraw Hill.

Sledzik, P. S., \& Bryson, S. W. (2016). Mass fatality management. In K.L. Koenig \& C.H. Schultz (Eds.), Disaster Medicine: Comprehensive Principles and Practices (pp. 361375). Cambridge University Press. http://dx.doi.org/10.1017/CBO9781139629317.026

Smith, J. F. (2010). Regional cooperation, coordination, and communication between airports during disasters. Transportation Research Record, 2177, 132-140. http://dx.doi.org/10.3141/2177-16

Summerhill, E. M., Mathew, M. C., Stipho, S., Artenstein, A. W., Jagminas, L. \& Russo-Magno, P. M. (2008). A simulation-based biodefense and disaster preparedness curriculum for internal medicine residents. Medical Teacher, 30(6), 145-151. http://dx.doi.org/10.1080/01421590802047257 